\title{
SIMULTANEOUS PVDF/VISAR MEASUREMENT TECHNIQUE FOR ISENTROPIC LOADING WITH GRADED DENSITY IMPACTORS
}

\author{
M. U. Anderson, L. C. Chhabildas and W. D. Reinhart" \\ Sandia National Laboratories, Albuquerque, NM 87185-14211 \\ "Ktech Corporation, Albuquerque, NM, 87110
}

\begin{abstract}
A simultaneous PVDF/VISAR measurement technique was used for isentropic-loading experiments with a polymethyl methacrylate (PMMA) specimen. The experiments used a graded density impactor accelerated onto a tantalum driver backed with PMMA and then lithium fluoride windows for each experiment. Simultaneous measurements made at each window interface provided precise transit time and particle velocity measurements which can be used to determine the stress-vs-strain loading path using Lagrangian analysis techniques. The experimental technique provides access to $40 \mathrm{GPa}$ stress levels in PMMA under isentropic-loading conditions.
\end{abstract}

\section{INTRODUCTION}

Shock loading techniques allow the capability for characterization of material properties at high pressures and strain rates'. During shock loading, a substantial temperature increase can accompany the pressure increase. The use of finite-rise-time loading produces quasi-isentropic compression of materials by introducing a series of small shocks that provide access to high pressure equilibrium states with lower temperatures than those obtained at Hugoniot shock states (quasi-isentropic loading will be referred to as isentropic loading in this paper for brevity, although isentropic loading is achieved only in the limit as the amplitude of each shock jump approaches zero).

A variety of isentropic-loading techniques have been developed that make use of the unique material properties of fused silica and glass ceramics to transform a shock input wave into an acceleration wave when used as buffer materials.
$(2,3,4)$ The stress limitations are approximately 3 and $20 \mathrm{GPa}$, respectively, due to their stress-strain behavior. (5) Graded density impactors have also been used for isentropic loading using both powder sedimentation techniques (6) and multiple layer impactors. $(7,8)$

The present technique development is intended to extend the level of stress achievable under isentropic loading by use of a multiply-layered, graded-density impactor accelerated onto a high impedance buffer material backed by the specimen and optical window. The material impedances and thicknesses in this technique were optimized with numerical simulations. There are two primary motivations for this technique development: material characterization under isentropic loading, and exploration of the response of the piezoelectric polymer PVDF under isentropic-loading conditions beyond the present limit of $10 \mathrm{GPa}$. (9) The present report describes the details of this isentropic-loading technique, and presents

' Sandia is a multi-program laboratory operated by Sandia Corporation, a Lockheed Martin Company for the USDOE under contract DE-AC04-94AL85000.

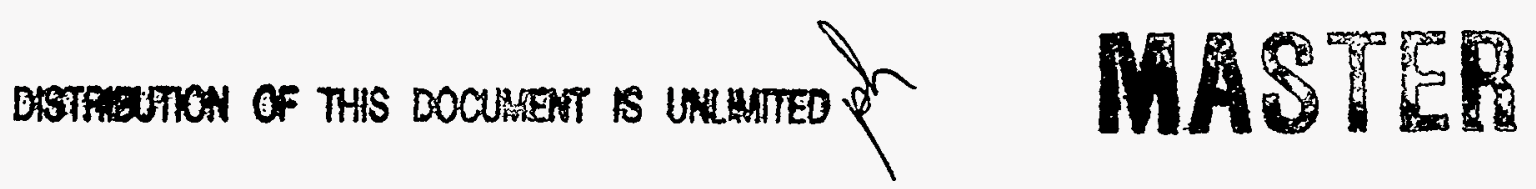




\section{DISCLAIMIER}

Portions of this document may be illegible in electronic image products. Images are produced from the best avallable original document. 


\section{DISCLAIMER}

This report was prepared as an account of work sponsored by an agency of the United States Government. Neither the United States Government nor any agency thereof, nor any of their employees, make any warranty, express or implied, or assumes any legal liability or responsibility for the accuracy, completeness, or usefulness of any information, apparatus, product, or process disclosed, or represents that its use would not infringe privately owned rights. Reference herein to any specific commercial product, process, or service by trade name, trademark, manufacturer, or otherwise does not necessarily constitute or imply its endorsement, recommendation, or favoring by the United States Government or any agency thereof. The views and opinions of authors expressed herein do not necessarily state or reflect those of the United States Government or any agency thereof. 
preliminary results that are encouraging in regard to the optical use of PMMA at high stress levels.

\section{EXPERIMENTAL TECHNIQUE}

Isentropic loading over the velocity range of 0.6 to $2.2 \mathrm{~km} / \mathrm{sec}$ was achieved by impacting a graded density impactor onto the tantalum driver-

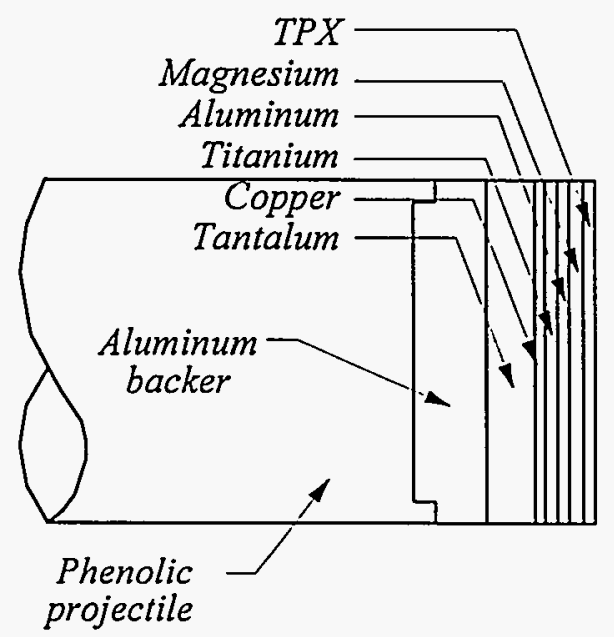

plate/specimen/window assembly to provide an isentropic loading to the specimen as seen in Fig. 1. The lithium fluoride window provides optical access to the specimen. The present study uses a polymethyl methacrylate (PMMA) specimen which provides optical access to the driver/specimen interface. PVDF sensors are mounted at each VISAR reflecting surface.

Figure 1. Isentropic-loading technique with multiple-layer laminated impactor accelerated onto tantalum driver in target. PMMA specimen is backed with lithium fluoride to allow optical access to front and rear surfaces of PMMA. Impactor layers increase in density and decrease in thickness from the TPX impact layer to the tantalum rear surface.

The simultaneous PVDF/VISAR measurement technique used in these measurements is based on the technique of Setchell $(10)$ and prior material response characterization of the high explosive HMX (11), employing both laser interferometer (VISAR) (12) and piezoelectric polymer (PVDF) (9) diagnostics in simultaneous measurements at two independent locations. The two independent VISAR measurements, when used in conjunction with the precise measurement of shock propagation time through the sample from the PVDF sensors, allow determination of the stress-vs-strain loading path of the specimen from the Lagrangian wave analysis method of Fowles and Williams. (13) This isentropic loading technique will also provide a method for examination of the loading-path effects on PVDF response at stress levels up to $40 \mathrm{GPa}$.

An 88-mm diameter, powder-driven, single-stage gun was used for these experiments. Projectile velocity was measured at impact with $\pm 0.5 \%$ accuracy. Measured tilt angle at impact is typically 1 milliradian or less. The graded density impactor was made from multiple layers laminated together, each layer having an increasing density and decreasing thickness from front to back. The aluminum backer is an integral part of the phenolic projectile. The experimental details of the impactor and target materials are listed in Table 1.

The mechanical shock impedance $(Z)$ of each material is defined as the product of the unshocked density $\left(\rho_{0}\right)$ and the $Y$ intercept from each material's tabulated $U_{s}-v s-u_{p}$ fit at $u_{p}=0$. The impedance of the impactor varies from $0.1326 \mathrm{gm} / \mathrm{cm}^{2} \mu \mathrm{sec}$ for TPX to $5.713 \mathrm{gm} / \mathrm{cm}^{2} \mu \mathrm{sec}$ for tantalum.

The tantalum driver thickness was chosen from numerical simulations to allow smoothing of the individual shock reflections at each interface layer within the graded density impactor. The thickness 
TABLE 1. Experimental configuration and dimensions for isentropic-loading technique.

\begin{tabular}{|l|c|c|c|c|c|}
\hline Exp\# & Impact vel. & Impactor material & Impactor thickness & Target material & Target thickness \\
\hline & $(\mathrm{mm} / \mathrm{usec})$ & & $(\mathrm{mm})$ & & $(\mathrm{mm})$ \\
\hline 51105 & 0.606 & $\mathrm{Ta} / \mathrm{Cu} / \mathrm{Ti} / \mathrm{Al} / \mathrm{Mg} / \mathrm{TPX}$ & $4.579 / .388 / .314 / .530 / .589 / 1.056$ & Ta/PMMA/LiF & $5.999 / .988 / 25.451$ \\
\hline 51123 & 0.911 & $\mathrm{Ta} / \mathrm{Cu} / \mathrm{Ti} / \mathrm{Al} / \mathrm{Mg} / \mathrm{TPX}$ & $4.506 / .391 / .312 / .528 / .587 / 1.064$ & Ta/PMMA/LiF & $6.337 / .967 / 25.350$ \\
\hline 51125 & 1.77 & $\mathrm{Ta} / \mathrm{Cu} / \mathrm{Ti} / \mathrm{Al} / \mathrm{Mg} / \mathrm{TPX}$ & $4.443 / .380 / .3191 .526 / .5911 .019$ & Ta/PMMA/LiF & $3.177 / .996 / 25.277$ \\
\hline 51124 & 2.12 & $\mathrm{Ta} / \mathrm{Cu} / \mathrm{Ti} / \mathrm{Al} / \mathrm{Mg} / \mathrm{TPX}$ & $4.443 / .379 / .317 / .518 / .597 / 1.022$ & $\mathrm{Ta} / \mathrm{PMMA} / \mathrm{LiF}$ & $1.983 / .997 / 25.209$ \\
\hline 51106 & 2.21 & $\mathrm{Ta} / \mathrm{Cu} / \mathrm{Ti} / \mathrm{Al} / \mathrm{Mg} / \mathrm{TPX}$ & $4.516 / .394 / .315 / .536 / .592 / 1.067$ & $\mathrm{Ta} / \mathrm{PMMA} / \mathrm{LiF}$ & $1.996 / .971 / 25.458$ \\
\hline
\end{tabular}

was constrained to prevent the high velocity tantalum reflected shock from the rear of the impactor to overtake the low velocity TPX shock, thus creating a shock jump input condition to the specimen. The tantalum thickness at the rear of the impactor was chosen to delay the shock release from the rear surface from overtaking the loading wave into the target.

VISAR measurements were made at the driver/specimen interface and the specimen/backer interface by depositing $2000 \AA$-thick reflecting surfaces over opposite halves of the two interfaces.

PVDF measurements were made in current-mode operation (14) with the recording instrumentation arranged to provide a common time-base between the two sensor locations.. The amplitude of piezoelectric current generated by PVDF in current-mode operation is proportional to the stress difference between the front and rear surfaces of the $25 \mu \mathrm{m}$ thick film. Shock arrival at the front surface of
PVDF generates a current pulse with a few nanosecond rise time to peak current, thus allowing a precise measurement of loading wave arrival times. Typical accuracy in transit time measurement is \pm 2 nanoseconds based on typical recording intervals of 1 nanosecond. The specimen transit time is calculated by subtracting shock transit times through the PVDF and insulation.layers using shock properties for each film.

\section{RESULTS}

The measured particle velocity profile at the front surface of the PMMA specimen shows initial shock jumps to $11 \%$ of the peak amplitude, followed by an acceleration loading that approaches isentropic compression of the specimen as seen in Fig. 2. The measured front-surface particle velocity reaches a maximum of $1.94 \mathrm{~mm} / \mu \mathrm{sec}$, corresponding to 40

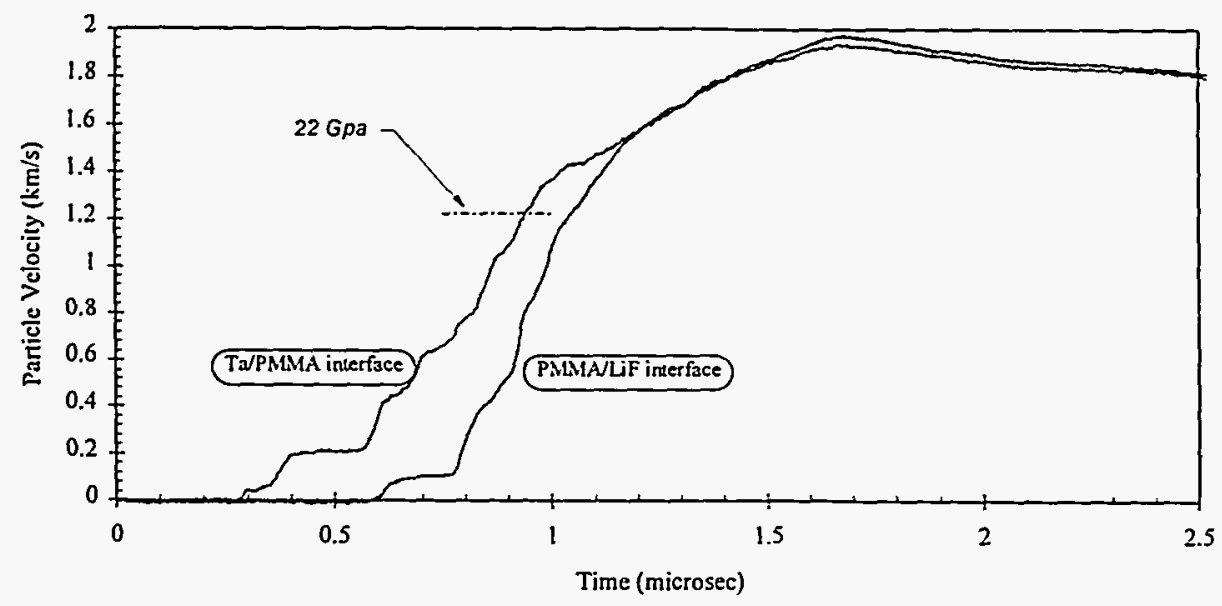

FIGURE 2. Particle velocity profiles from front and rear surfaces of PMMA specimen under isentropic loading. Mechanical equilibrium is achieved within specimen before release arrives. $22 \mathrm{GPa}$ transparency limit for shock loading is shown. 
$\mathrm{GPa}$, well beyond the $22 \mathrm{GPa}$ limit for transparency under shock-loading. (15)

The overlaid measurement profiles from front and rear specimen surfaces show that equilibrium is achieved within the specimen before release arrives.

The desired result from these isentropic-loading experiments is stress-vs-strain loading paths for PMMA up to $40 \mathrm{GPa}$. The Langrangian analysis used to calculate stress-vs-strain paths (12) makes the assumption that the wave velocity for any given level of particle velocity is constant. Multiple thicknesses of specimens need to be studied at the same input conditions in order to satisfy this assumption. Analysis of the present data is in progress.

The PVDF measurements are not shown due to an unanticipated complication. The PVDF response was obscured at high stress levels by the shockinduced polarization of the uninsulated PMMA specimen. The onset of shock-induced polarization from the PMMA specimen was observed at $1.0 \mathrm{GPa}$ superposed onto the piezoelectric current generated from the PVDF sensor, thereby preventing the observation of quantitative stress histories. Accurate arrival times were measured at low stresses only. This observation demonstrates the need for electrical insulation and shielding of the PMMA specimen. Teflon insulation is typically used due to the low level of piezoelectric activity $\left(10^{-7} \mathrm{C} / \mathrm{m}^{2}\right)$, in contrast to PMMA $\left(10^{-4} \mathrm{C} / \mathrm{m}^{2}\right)$ which is larger by 3 orders of magnitude. (16)

\section{CONCLUSIONS}

This simultaneous PVDF/VISAR measurement technique combined with the isentropic-loading technique provides the capability for exploring the isentropic response of materials to higher stresses. PMMA appears to remain transparent during isentropic-loading to $40 \mathrm{GPa}$. Care must be taken to properly insulate the PVDF gauges when using samples that may show high-stress piezoelectric behavior.
The authors thank Heidi Anderson for her talented preparation of the experimental assemblies and R. E. Setchell for the manuscript review.

\section{REFERENCES}

${ }^{1}$ Davison, L. W., R. A. Graham, Phys. Rep., 55, pp. 257-379 (1979).

${ }_{2}^{2}$ Barker, L. M., R. E. Hollenbach, J. Appl.

Phys., 41, pp. 4208-4226 (1970).

${ }^{3}$ Setchell, R. E., Combustion and Flame, 54, pp. 171-182 (1983).

${ }^{4}$ Germain-Lacour, M., M. de Gliniasty Shock Woves in Condensed Matter-1981, AIP, pp. 481-485. (1981).

${ }^{5}$ Asay, J. R., L. C. Chhabildas, High Pressure Science and Technology, Pergamon Press, pp. 958-964 (1980).

${ }^{6}$ Barker, L. M., Shock Waves in Condensed Matter-1983, North-Holland, pp. 217-224 1982).

${ }^{7}$ Adadurov, G. A., and V. I. Gol'danskii, C. $M$. Backman, T. Johannisson and L. Tegner, V1, Arkitektkopia Sweden, pp. 18-32. (1982).

${ }^{8}$ Chhabildas, L. C., J. R. Asay, and L. M. Barker, SAND88-0306, Sandia Nat. Lab. ${ }^{9}$ Graham, R. A., M. U. Anderson, F. Bauer, and R. E. Setchell, Shock Compression of Condensed Matter-1991, North-Holland, pp. 883-886 (1992).

${ }^{10}$ Setchell, R. E., Shock Woves in Condensed Matter-1987, pp. 623-626 (1988).

"Anderson, M. U., and R. A. Graham, Shock Compression of Condensed Matter-1995, pp. 1101-1104 (1996).

12 Barker, L. M. and R. E. Hollenbach, Rev. Sci. Instrum., 36, pp. 1617 (1965).

${ }^{13}$ Fowles, G. R., and R. F. Williams, J. Appl. Phys. 41, pp. 360 (1970).

${ }^{14}$ Anderson, M. U., D. E. Wackerbarth, R. A. Graham, Shock Compression of Condensed Matter-1989, pp. 805-808 (1990).

${ }^{15}$ Chhabildas, L. C., H. J. Sutherland, and J. R. Asay, J. Appl. Phys., 50, pp. 5196-5201, (1979).

${ }^{16}$ Graham, R. A., J. of Phys Chem. 83, pp. 3048-3056, (1979). 